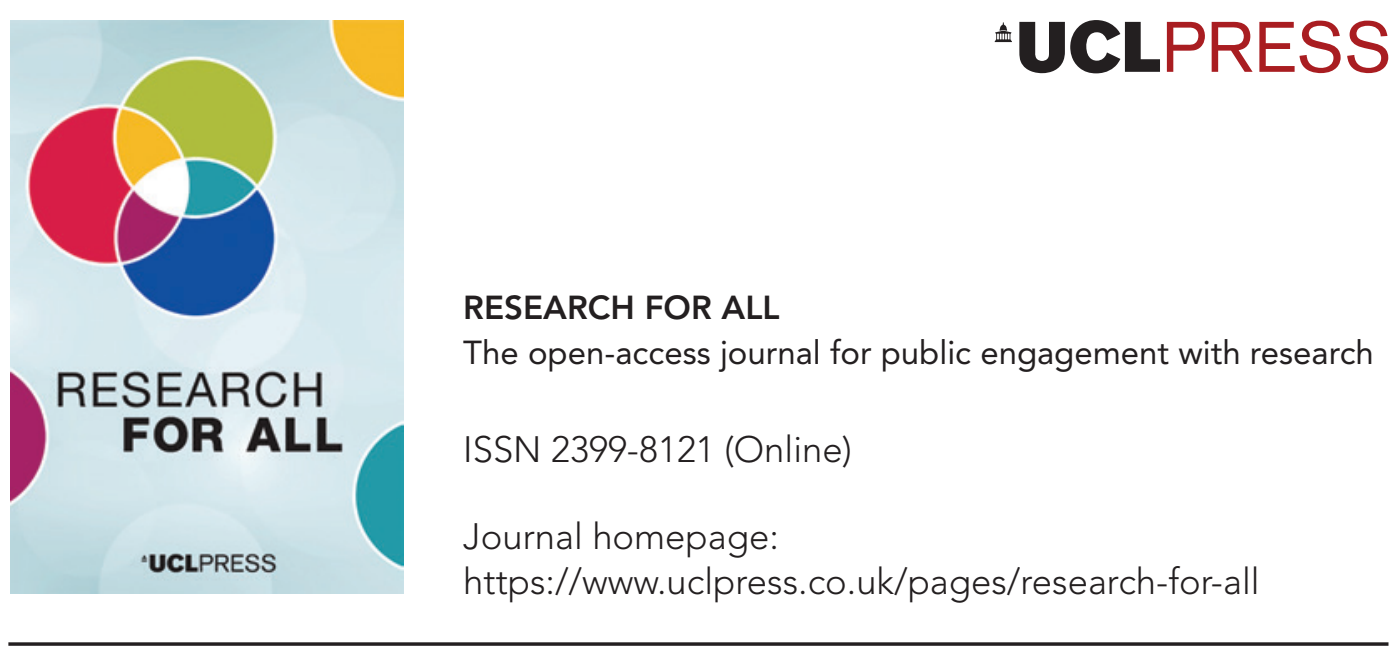

\title{
Meeting the challenges of public engagement, research impact and research participation as a baby and child lab
}

\author{
Gideon Salter (D), Tina Altdörfer, Geraldine Brown and Malinda Carpenter (iD
}

\section{How to cite this article}

Salter, G., Altdörfer, T., Brown, G. and Carpenter, M. (2021) 'Meeting the challenges of public engagement, research impact and research participation as a baby and child lab'. Research for All, 5 (2), 420-37. https://doi.org/10.14324/RFA.05.2.15

Submission date: 10 October 2020

Acceptance date: 18 March 2021

Publication date: 21 September 2021

\section{Peer review}

This article has been peer-reviewed through the journal's standard double-blind peer review, where both the reviewers and authors are anonymized during review.

\section{Copyright}

(C) 2021 Salter, Altdörfer, Brown and Carpenter. This is an open-access article distributed under the terms of the Creative Commons Attribution Licence (CC BY) 4.0 https://creativecommons. org/licenses/by/4.0/, which permits unrestricted use, distribution and reproduction in any medium, provided the original authors and source are credited.

\section{Open access}

Research for All is a peer-reviewed open-access journal. 


\title{
Meeting the challenges of public engagement, research impact and research participation as a baby and child lab
}

\author{
Gideon Salter* - School of Psychology and Neuroscience, University of \\ St Andrews, UK \\ Tina Altdörfer - Leipzig Research Centre for Early Child Development, \\ Germany \\ Geraldine Brown - School of Psychology and Neuroscience, University of \\ St Andrews, UK \\ Malinda Carpenter - School of Psychology and Neuroscience, University \\ of St Andrews, UK
}

\begin{abstract}
As well as conducting research in developmental science, baby and child labs face additional pressures. They must demonstrate public engagement and research impact, while also recruiting enough participants to conduct research, something that can be particularly challenging with infants and young children. These different pressures compete for time and resources, leaving researchers struggling to engage effectively in all such activities. Here we describe a lowcost, easy-to-implement, enjoyable and effective means of simultaneously addressing the challenges of recruitment, public engagement and research impact. It started with a process of listening and knowledge exchange with relevant local stakeholders to discern the interests and needs of the local infant community (including families, health professionals and businesses). This process led to the establishment of a fortnightly educational and support group for pregnant women and mothers of young infants, which met in the lab. This group combined peer discussion, presentations on developmental psychology, and 'taster' activities for mothers and infants from local businesses. Data collected from questionnaires from the first and final sessions indicated significant improvements in participants' understanding of relevant concepts in developmental psychology, and showed that participants found this information helpful and reported using it at home. Participants also reported feeling more socially connected and more confident as mothers as a result of the group. The group also served to boost research participation, with 94 per cent of participants subsequently taking part in lab research or signing up to be contacted about future research. This approach can be employed by baby and child labs looking for ways to effectively and enjoyably promote public engagement and research impact, and for those looking to establish strong relationships with local stakeholders. The success of this strategy demonstrates that the aims of recruitment, public engagement and research impact need not be competing pressures on researchers' time, but can be mutually supporting aspects of the research process.
\end{abstract}

Keywords: public engagement, research impact, recruitment, baby and child labs 
Key messages

- Baby and child labs have unique opportunities to engage families with research.

- Families with infants are interested in hearing about scientific research in developmental psychology, and value and use what they learn from this discipline.

- Recruiting participants, conducting research, and engaging in public outreach and impact can be mutually supporting, rather than competing, activities.

\section{Introduction}

There are increasing calls to shift scientists' attitudes towards public engagement and science communication from seeing it as an unpopular and niche activity to seeing it as an important aspect of academic life (Besley et al., 2018; Ecklund et al., 2012). A recent report by the National Co-ordinating Centre for Public Engagement (NCCPE) in the UK suggested that 'a culture of engagement is beginning to take hold and is strengthening' in UK higher education (Wilson et al., 2014: 6). Focusing on psychology departments, Hagger-Johnson and colleagues (2013: 664) stated that 'Public engagement and knowledge transfer are now necessary supplements to academic research and teaching activity for university-based psychologists in the United Kingdom.' Researchers are also increasingly required to demonstrate 'research impact', which can be broadly defined as the demonstrable contribution that research makes to society. Public engagement and research impact are not interchangeable terms, but they are closely connected: effective public engagement is often a means of demonstrating research impact.

The value of such activities is increasingly becoming institutionally recognized and, in some cases, mandated. For example, in the UK, a number of key funders and institutions have formally committed to encouraging and supporting public engagement in UK research institutions (RCUK, 2010). Demonstrating research impact accounts for 25 per cent of the assessment criteria in the all-important nationwide review of universities, the Research Excellence Framework (REF), the outcome of which strongly influences the allocation of public funds for UK universities (REF2021, 2020). Similarly, the European Research Council (ERC) states that 'outreach activities are a must' for any of its grant holders (ERC, 2019), and prizes were awarded to Horizon2020 grant recipients who demonstrated exceptional research impact (EC, 2020). Grant proposals to the National Science Foundation (NSF), a key funder of scientific research in the United States, are required to include plans for ensuring 'broader impacts', which involves demonstrating how the research will provide benefit to society beyond academia, and includes the requirement to conduct public engagement activities (Besley et al., 2015).

However, while many researchers across different nations may buy into the value of public engagement for a variety of reasons (Duncan and Oliver, 2017; Wilson et al., 2014), there are practical obstacles to actual participation. A recent study found that three key predictors of science researchers' willingness to take part in public engagement activities were: (1) researchers' available time; (2) whether researchers felt that they would enjoy the activity; and (3) whether researchers felt that their efforts would be effective (Besley et al., 2018). The aims of effective science communication can be summarized by Burns and colleagues' (2003) 'AEIOU' model: to generate 
Awareness, Enjoyment, Interest, Opinions and Understanding. We would argue that developmental psychology is an area of study that is well suited to achieving these goals, given the broad appeal and relevance of issues relating to child development.

Along with the challenges of public engagement and impact, researchers who study child development face an additional challenge: that of participant recruitment. It is usually important to recruit infants or children within a very specific age range, and because participant databases are filled with participants who are ageing out of those age ranges every day, a constant stream of new recruits is needed. Brand and colleagues (2019) reported widespread difficulty and frustration among developmental psychologists in this area. In one of their surveys $(n=119), 35$ per cent of researchers in the field were 'somewhat dissatisfied' or 'extremely dissatisfied' with their recruitment rates, and 43 per cent reported that slow recruitment limited the kind of research that they were able to undertake. This challenge is particularly pronounced in labs that are not located in or near high-population, urban areas. 'Scattergun' strategies (many targets, low response rate) such as cold calling and social media advertisements are likely to be even more ineffective there than they are in high-population areas (Brand et al., 2019). Our lab is situated in such an area, and we indeed found this to be the case in our early recruitment efforts. We suggest that for baby and child labs, and potentially for other research groups too, the pressure of recruitment can serve as a barrier to conducting public engagement activities.

Here we describe a strategy, 'ABC Communities', that provides a successful example of how to simultaneously address the challenges of public engagement, research impact and recruitment. It also has the additional, and no less important, benefit of increasing well-being in participants. The approach is one that is enjoyable for researchers and is demonstrably effective. It involved two key stages, as we detail next.

\section{ABC Communities: Listening and providing}

\section{Stage 1: Listening to the infant community}

The first stage of this approach involved listening, first and foremost, to parents of infants, but also to those who work with infants in some capacity in our local area. This included public sector workers (midwives and birth registrars, for example), charity workers, local business owners, and day-care providers. We use 'infant community' as a shorthand way of referring to those involved in the lives of infants in some capacity (while recognizing the particular importance of parents; see WHO, 2002).

This initial 'listening' stage involved consulting the local infant community to learn about their positive and negative experiences in the town. We chatted with parents when we visited local groups and activities, and asked them about their experiences, positive and negative, as parents in the area. We also spoke with friends and colleagues with infants to get informal insights into the experience of looking after a baby in the area. A few interested parents came to the lab for a tour and a chat about what we do over a cup of tea or coffee. We also spoke to individuals and groups that work with infants in the area. This included day-care centres, playgroups, charities, businesses (science museums and 'baby yoga' classes, for example), and public sector workers such as health professionals and members of the local birth registry team. We visited their groups and places of work to see what these activities were like, and invited activity leaders and public sector workers to visit our lab. 
This process culminated in a 'knowledge exchange' event in our lab. A diverse range of around fifteen representatives from the local community attended, several of whom were parents themselves in addition to working with infants in some capacity. At the event, drinks and snacks were provided, and networking among the different participants was encouraged. Stimuli from previous studies were put on display, with information about what we had learned about child development from each study. Members of the research group were there to answer questions from participants. Lab members then gave a short presentation that introduced the members of our team and the kind of research we conduct. This was followed by a semi-structured open discussion about how our lab could support the local infant community, and questionnaires were handed out to get further feedback on this theme.

The listening stage was key. It ensured our approach to engaging the local infant community was not one of linear knowledge transfer, but rather an interactive, multidirectional approach (Ward et al., 2009). By first hearing from others, we were able to learn what the actual needs of the community were, which allowed us to more effectively share knowledge and offer support. In doing so, we sought to avoid a 'deficit model' of public understanding (Hagger-Johnson et al., 2013); that is, rather than presuming a lack of knowledge, the knowledge and opinions of the community were respected and listened to. The process prevented us from wasting time on ideas that, although worthy in principle, were ultimately not necessarily wanted or needed. It also allowed us to foster personal relationships that continued to grow over subsequent months, and to continue to draw upon these relationships to ensure a stakeholder-led approach to the activities and resources we would provide. This process naturally required an investment of time, but in our situation (establishing new community connections and recruiting infants in a low-population area), the time investment paid off.

Through the insights gained from discussions with the local infant community, and through the knowledge exchange event in particular, we identified two principal needs in our community. First, both parents and local groups alike felt that there were relatively few clear channels of communication, making it a challenge to link families to the groups and activities that they might enjoy and from which they might benefit. Second, parents repeatedly commented that there were few organized activities specifically for pregnant mothers and those with young infants (around 0 to 6 months). We addressed these needs in the second stage.

\section{Stage 2: Providing for the infant community}

Having listened to the needs of the infant community, we next considered ways in which we could realistically meet their needs. We found two areas in which we were well-placed to help.

The first was in providing ways for the infant community to be better connected. This was both in terms of different families connecting with each other, and in terms of families connecting with local groups and businesses. Families were not always sure where to make social connections. Businesses found it difficult to find effective ways to advertise, and parents often described not knowing where to look for information about local activities. These challenges were particularly pronounced for families who were new to the area, a not-infrequent situation given the transient nature of the local student population.

In response to these needs, we launched two online resources. First, we created a Facebook page titled 'ABC Lab Communities', designed to be a place where individuals and organizations could share information about local activities for families 
with infants. To try to encourage as much community participation as possible, we contacted those groups and businesses with whom we had formed a relationship, and encouraged them to post their activities on the page. These posts then appeared to group members, who could follow the links to find out more information or sign up for activities (see Figure 1). We chose to make the group private to try to ensure that only relevant individuals and organizations could join. Within a few months, it had over a hundred members, with information and activities being shared by businesses, daycare centres, charities and individuals.

Second, we launched a similar resource on our own lab website. Rather than a constantly updating flow of information, this is a static resource with the aim of helping recently arrived families and new parents connect to local groups and activities. Producing the Facebook page and website involved a relatively small allocation of time and was entirely free. Some members of the lab give an hour or so each week to curate the Facebook page. A volunteer research assistant took on the web resource as a project, and it is sporadically updated when new activities are launched or discovered. Despite the minimal time investment, the payoff has been significant. By functioning as a conduit through which local individuals and organizations can connect, our lab became a familiar name in the community, and filled a unique niche in the local area.

The second area of need was for pregnant women and parents of young infants. While the town benefited from a number of popular playgroups and activities for young children, these were less suited to smaller babies. The generally high level of noise, and fear of boisterous toddlers trampling on infants, put off parents of babies who were unable to sit unsupported or crawl. Additionally, local parents informed us

\section{Figure 1: Sample (anonymized) interaction between a local business and a local parent taken from the ABC Lab Communities page (source: author)}

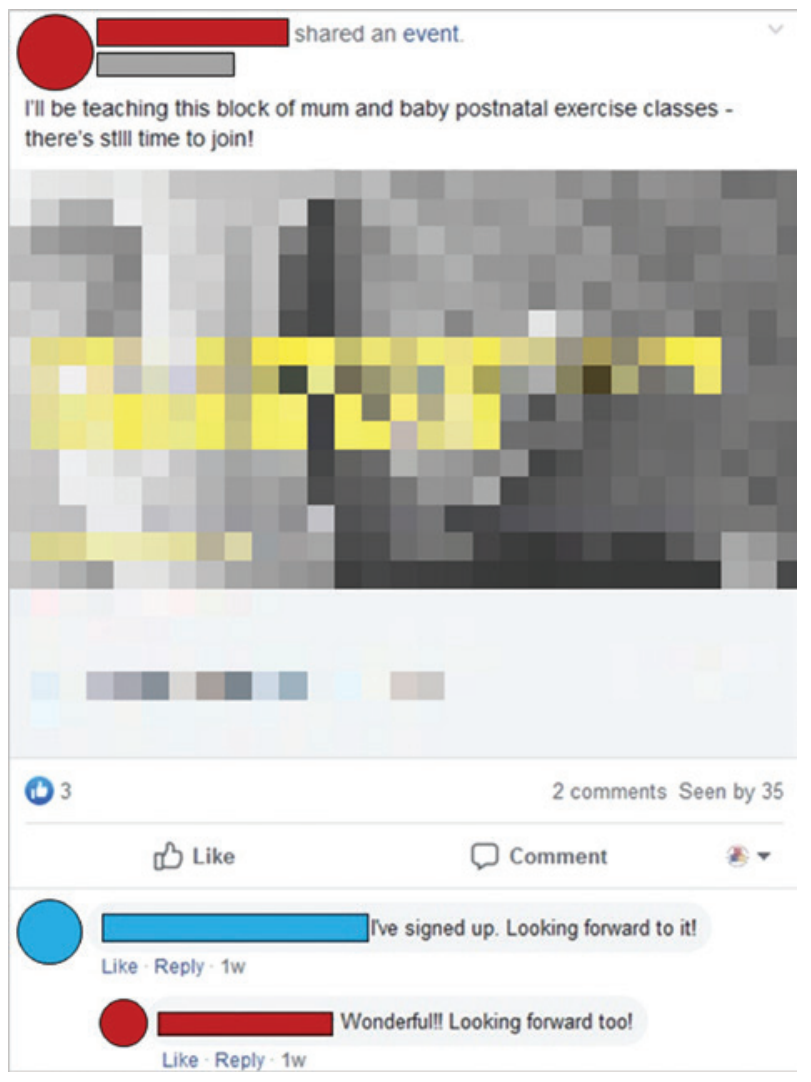


that they had been negatively affected by the recent closure of a local family-friendly café that had served as a social hub for families with infants and young children. Along with taking away a safe play space, it is likely that this also disrupted opportunities for knowledge exchange among peers, which has been shown to be a key source of information for mothers (Loudon et al., 2016).

With these insights in mind, we created a fortnightly educational and support group meeting for pregnant women and mothers of young infants (hereafter 'mothers') in our lab: the ABC Baby Bee. Mothers were recruited through the online pages we had created, through leaflets distributed to relevant locations (for example, a local museum, the local library and local businesses), through word of mouth, and through the university's internal newsletters. While some of the mothers who joined had been involved in the listening stage, the majority were first reached through these recruitment efforts. We applied for and received 'impact funding' from the university to cover the costs of the materials such as mats, toys and refreshments. This also enabled us to offer reimbursement for mothers' parking costs when needed.

The aim was for the group to be a space in which there could be open peer discussion about the joys and challenges faced during pregnancy and early motherhood. In order to encourage this kind of discussion, we set the maximum group size to 15 to allow all members to get to know one another and feel more relaxed about sharing their experiences. Initially, the group was only for mothers, not fathers, in order to enable more open discussions of the unique issues that mothers face such as birth and breastfeeding, but future plans include creating a group for fathers as well. We also restricted the group to infants that were not yet mobile to ensure that mothers would feel comfortable bringing their young babies. We provided childcare for older siblings in an adjoining room, enabling mothers with multiple children to attend.

In the main room, chairs were arranged around the edge, with large mats in the middle (see Figure 2). Cushions and mats on the floor allowed mothers to sit with their babies, while toys and 'baby gyms' provided the babies with entertainment. Over the course of the sessions, the group adjusted to a circular arrangement, with babies lying in the middle and mothers around them. Mothers felt that this was the optimal arrangement, such that all group members felt included.

At a distance from the mats, tea, coffee and snacks (provided by the university) were available. At the beginning of each session, mothers entered the space, took any refreshments they wanted, and sat around the room. The first twenty minutes of every session were given to informal peer interaction. Members of the lab team who were themselves experienced mothers sat with the mothers in attendance, interacting

\section{Figure 2: Set-up of lab space for the Baby Bee sessions (source: author)}

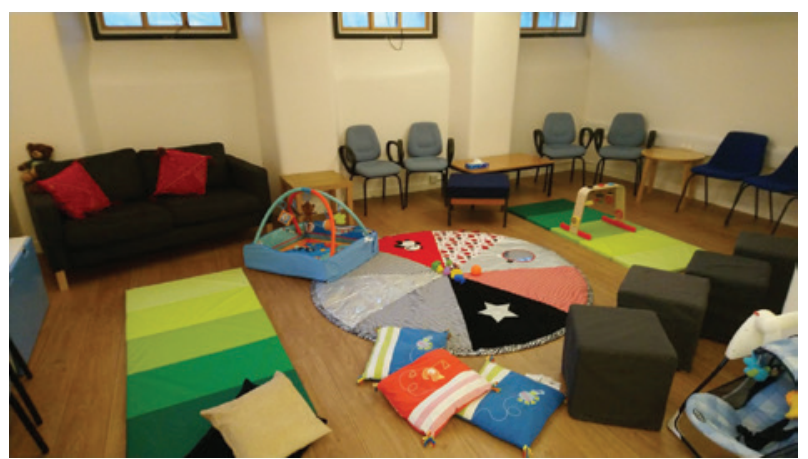


with their babies and chatting. We did not explicitly select conversation topics, but discussions about the experiences of motherhood were commonplace.

The next ten minutes or so consisted of a taster session for a local business. For example, a local Pilates instructor demonstrated helpful stretches for post-partum mothers and answered questions about exercise during the months after birth. The taster sessions allowed mothers to get a sense of the activities to which they might sign up in a relaxed, no-pressure atmosphere, and gave the business leaders a chance to get to know new mothers who might be interested in their activities.

We sought to ensure an ethical approach to business involvement. Invitations to businesses were made based on personal, local connections, and the invited businesses were specifically those providing relevant, helpful activities of various kinds, such as exercise or cognitive stimulation for babies, and they all had a social (that is, group interaction) component to them. Researchers from the lab had visited all the invited businesses in person to view the activities and to ensure that the activities would be appropriate and enjoyable. The taster sessions did not mention the activity prices to minimize the possibility that a participant would feel uncomfortable or alienated by this. Instead, they were presented as fun activities that parents could try with their babies during the session and at home.

Another aim of the group involved public engagement with research and enhancing our research impact. Thus, towards the end of the session, following another period of informal peer interaction, we provided a short (approximately ten minutes), informal presentation with helpful information about relevant findings from developmental psychology. These presentations fitted the overarching theme of shared experience, as a topic that was within our expertise and relevant to mothers. The theme of shared experience connected naturally with the research programme of the authors. It also fitted with one of the community needs that we were seeking to address - namely, the lack of dedicated spaces in which pregnant women and mothers with young infants could meet and share their common experiences. We then selected relevant research topics within this overarching theme to discuss, such as imitation, joint attention and communication. A local governmental health professional with whom we had established connections also kindly contributed to the educational component of one of the meetings by providing a presentation and discussion about some practical issues that the mothers had identified as important to them, such as sleep and breastfeeding. Throughout, we noted that it is normal for infants to develop in different ways and at different rates, and if participants had expressed concerns about their baby's development, we would have referred them to health professionals. Participants were free at any time to move into an adjacent room (and frequently did so to change or feed their baby), meaning that if they found any part of any of the discussions uncomfortable, they could easily leave. However, this was not something that occurred - all mothers chose to remain in the main room to listen to the presentations.

The group was initially launched as a set of six sessions, with a session every two weeks. This was enough time to see if the group was having an impact, but not an overly long commitment for the mothers and infants (or ourselves, in case the group did not work well). Each session was 90 minutes long, allowing time for the taster sessions and educational components, as well as plenty of time for mothers to chat to one another (see Table 1). We limited the taster sessions and presentations to around ten minutes, although speakers remained throughout the sessions to speak to mothers and to answer any further questions. However, we also sought to be flexible, sometimes having the presentation earlier in the session, and sometimes allowing discussions to 
Table 1: Approximate, flexible timetable for each session

\begin{tabular}{ll}
\hline Time & Activity \\
\hline 10:30-10:50 & Arrival, peer interaction \\
10:50-11:00 & Taster session \\
11:00-11:40 & Peer interaction \\
$11: 40-11: 50$ & Lab presentation \\
$11: 50-12: 00$ & Peer interaction, mothers and infants leave \\
\hline
\end{tabular}

continue with the speaker or taster provider. Sessions took place on Friday mornings from 10:30 a.m. to 12:00 p.m. This time was chosen as the optimal time slot by the mothers who responded during the recruitment phase.

Volunteer students were recruited to look after any siblings in an adjacent room of the lab, which enabled mothers with multiple children to attend. The students read stories and played games with the older children, providing a fun way for the students and children alike to be involved with the lab. This allowed mothers to be together in the adjoining room with their sole focus on their infants.

To measure the impact and effectiveness of the group on mothers' knowledge and well-being, we created a questionnaire. This enabled us to understand the issues faced by the group members in more detail. It also provided us with input that could make future instantiations of the group even more useful. The questionnaire had two parts, one that was completed by mothers at the first session, and the other at the final (sixth) session. We present the findings of the questionnaire below.

\section{The Baby Bee questionnaire}

\section{Participants}

Of the 15 participants in the group, 14 mothers completed the initial questionnaire (4 aged $21-30$ years; 10 aged 31-40 years). Of these mothers, 11 completed the final questionnaire (3 aged 21-30 years; 8 aged 31-40 years). Two of the mothers were pregnant at the time of completing the initial questionnaire; all mothers who completed the final questionnaire had given birth. No socio-economic status, employment or education data were collected directly from participants, but data from a national index (Scottish Government, 2016) that takes into account a range of information on health, unemployment and income to identify the relative deprivation of different regions in the country indicated that in the local area, scores ranged from the fourth decile (within the 40 per cent most deprived areas nationally) to the eighth decile or higher (within the 20 per cent least deprived areas nationally), indicating significant variability in socio-economic status within the local community.

\section{Procedure}

Mothers were given a questionnaire at the start of the first session and at the end of the final session. They were made aware that participation in the group was not contingent on completing the questionnaires, and they gave their informed consent. The questionnaires combined a mixture of multiple-choice questions and open-ended response questions. We report the results of many but not all of the questions below, as some questions were less directly relevant to the themes discussed in this paper. Full questionnaires are available by request to the first author. 
For the multiple-choice questions, we provide percentages of responses. For the open-ended questions, we grouped responses into relevant themes. Respondents could list as many answers as they wanted, meaning that there were frequently several different themes within a given response. However, a given response was not scored for the same theme more than once. We provide the percentages of responses that included each theme. Not all the questions were answered by all of the participants, and in such cases we have indicated the number of respondents.

Participant numbers in the following data are admittedly small. However, our primary aim was to create a social group for peer support, and thus the group size was intentionally limited to ensure that social connections could be formed among the group as a whole. Thus, our purpose here was not to conduct a large-scale study to be generalized to any baby lab. Rather, it was to provide a proof-of-concept for our participatory approach, which would need to be adapted from context to context.

\section{Results and discussion}

\section{Questionnaire 1}

The aim of the first questionnaire was twofold. First, we wished to gain insights into the experiences of mothers in the area, with a particular focus on their social and wellbeing needs. Based on our experiences listening to the community, and from the knowledge exchange event, we hypothesized that mothers in the area were looking for ways to meet others at the same stage of motherhood who were facing similar experiences and challenges. Second, we wished to establish participants' interests regarding the educational component of the group, and their prior knowledge of terms in developmental psychology, especially those associated with the theme of shared experience. This was done to provide a baseline measure for later assessing the educational impact of the group.

\section{Participants' social needs}

We first asked mothers several questions about social connectedness in the local area. Table 2 displays two questions relating to this theme, with participants' responses.

The results indicate that while there were mixed responses regarding the ease with which participants were able to make social connections, the vast majority of participants (93 per cent) wanted more opportunities to meet peers. This fits with Brand and colleagues' (2019) observation that families can struggle to find childfriendly spaces in which to meet.

\section{Table 2: Questions and responses relating to local social connectedness}

\begin{tabular}{ll}
\hline Questions & Responses (\%) \\
\hline How easy do you find it to make social connections/ & Very easy (36) \\
friendships in the area? & A little easy (21) \\
& Neither easy nor difficult (7) \\
& A little difficult (29) \\
& Very difficult (7) \\
Do you think it would be good to have more opportunities to & Definitely yes (72) \\
meet up with other mums with new babies and/or expectant & Probably yes (21) \\
mums? & Might or might not (0) \\
& Probably not (7) \\
& Definitely not (0) \\
\hline
\end{tabular}




\section{Participants' educational aims and knowledge}

We also asked mothers about topics for which they would particularly appreciate information from experts, and we used these responses to help guide the content of the educational sessions we ran. We further asked whether there was anything else mothers hoped to get out of the group. Responses were open-ended, and are listed in Table 3.

The responses indicate that themes of feeding (82 per cent), sleep (64 per cent) and health/safety (55 per cent) were most pressing to the mothers. We opted to draw on outside help from a health professional to address these themes, as they were outside our areas of research expertise.

The majority of the group ( 85 per cent) hoped that the group would provide benefits relating to friends/social life. It is relevant to note that 27 per cent of those who selected friends/social life spontaneously highlighted specifically that they were hoping to make 'mom friends', tying to our earlier point that mothers would like to make more friends who face common experiences and challenges.

Finally, in order to later formally assess the impact of the group, before we started the educational component of the sessions, we needed to know whether the mothers were familiar with some key terms in developmental psychology, particularly those linked to the theme of shared experience. Figure 3 shows maternal reported knowledge of six key terms when asked in Session 1.

\begin{tabular}{ll}
\hline \multicolumn{2}{l}{ Table 3: Participants' desired outcomes from the group } \\
\hline Questions & Responses (\%) \\
\hline What types of experts would you like to hear & Feeding (breastfeeding, weaning, etc.) (82) \\
from, and what kind of information would be & Sleep (64) \\
most valuable to you and your baby? & Health/safety (55) \\
& Developmental research (27) \\
& Other (27) \\
What else do you hope to get out of the Baby & Friends/social life (85) \\
Bee meetings? & Education on development from the lab (38) \\
(Note: 13 respondents) & Learning from other mothers (23) \\
& Stimulation and fun for baby (15) \\
\hline
\end{tabular}

Figure 3: Mothers' responses to the question 'Have you heard of the following terms in developmental psychology?' (source: author)

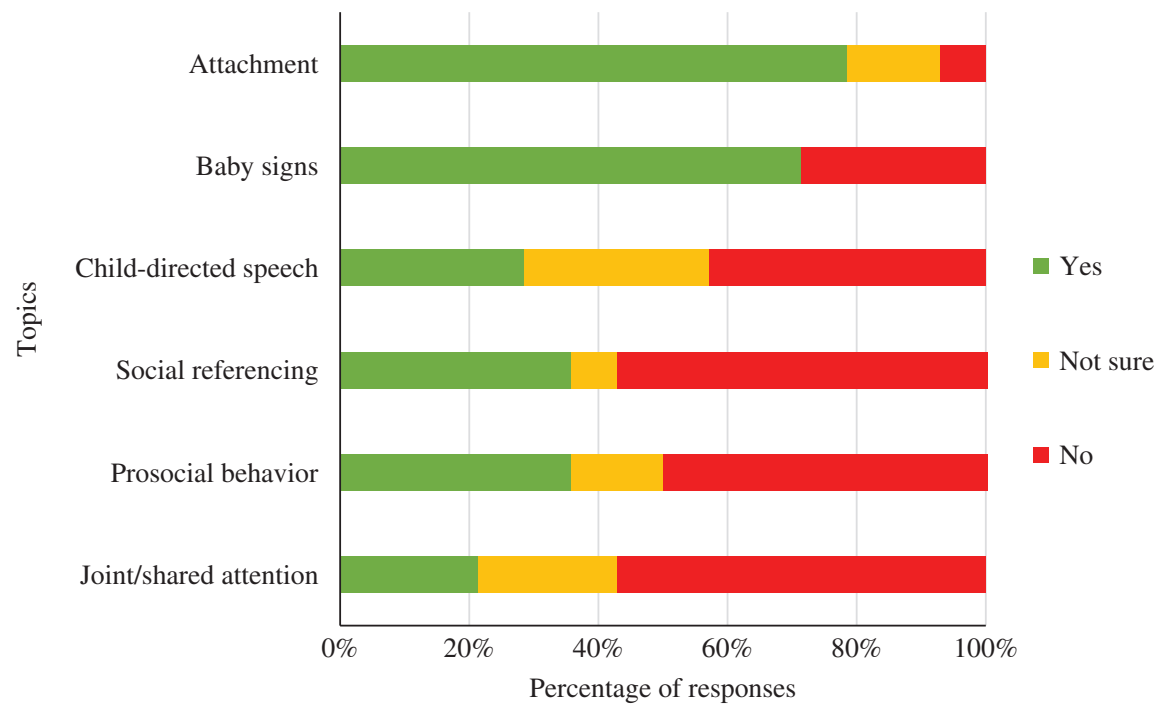


We chose the phrasing 'Have you heard of ...', rather than, for example, 'Explain the following ...'. We did not want mothers to feel under pressure to explain terms, or for the questionnaire to get overly long. While it is possible that mothers who chose 'Yes' only had a broad familiarity with the terms, the results provide a suitably accurate representation of the mothers' knowledge.

The majority of mothers were familiar with the terms attachment and baby signs. It is possible that these topics are emphasized to new parents by midwives and/or health professionals, or that they have also received more mainstream publicity than the other terms. Most mothers were unfamiliar with the terms child-directed speech, social referencing, prosocial behaviour and joint/shared attention. These terms, while key in developmental psychology, were clearly not initially widely known to group members.

In response to the group members' interests, and following our own aims for the group and our research expertise, we chose the themes listed in Table 4 for the educational sessions. We addressed all the topics above, although some more briefly than others.

\section{Summary}

The overall picture provided by the first questionnaire matched our initial predictions. Although roughly half of the group felt that they were able to make social connections, the vast majority of the group, including those who already felt socially connected, wanted more opportunities to meet other mothers of young infants and saw this as extremely important. The responses also provided a helpful baseline indication of mothers' knowledge, allowing us to assess how well the educational component of the group worked.

\section{Questionnaire 2}

There were two main aims for the second questionnaire: (1) to assess the effectiveness of the group in improving mothers' social connectedness and sense of well-being; and

\section{Table 4: Educational session topics}

\begin{tabular}{lll}
\hline Session & Title & Description \\
\hline 1 & Introduction & We introduced the team, the general aims of the \\
group and the theme of shared experiences.
\end{tabular}


(2) to assess the effectiveness and helpfulness of the educational component of the group. Along with the questionnaire data, we also assessed the effects of the group on recruitment of infants as participants in research being conducted in our lab.

\section{Well-being and education benefits of the group}

Table 5 lists the degree to which participants agreed or disagreed with a number of statements regarding the well-being and education benefits of the group. Results indicate that the majority of mothers felt that the group was beneficial in both domains.

For example, the majority ( 91 per cent) of mothers agreed with the statement 'Having been to the Baby Bee sessions, I now feel more confident with the practical aspects of looking after my baby (helping him/her sleep, feeding, etc.)'. This was a key area of interest for mothers, as indicated in the initial questionnaire; that is, a large percentage of the mothers had highlighted practical concerns as being important to their well-being, and had requested a discussion of such issues as part of the educational programme (see Table 3). We were able to address these topics with the help of the local health professional's presentation, and through the conversations among mothers. This link between shared experience and confidence is expressed in comments from the participants, who said, for example, 'I liked being able to talk to

Table 5: Participants' responses to statements regarding well-being and education benefits of the group

Statements
The Baby Bee sessions increased my confidence as a mother.

The Baby Bee sessions increased my confidence as a mother.

activities for babies.

The Baby Bee group helped me to make new social connections.

Having been to the Baby Bee sessions, I now know more about my baby's social and psychological development.

Having been to the Baby Bee sessions, I now feel more confident with the practical aspects of looking after my baby (helping him/her sleep, feeding, etc.)

\section{Responses (\%)}

Strongly agree (9)

Agree (82)

Not sure (9)

Disagree (0)

Strongly disagree (0)

Overall agree (91)

Strongly agree (36)

Agree (55)

Not sure (9)

Disagree (0)

Strongly disagree (0)

Overall agree (91)

Strongly agree (55)

Agree (36)

Not sure (9)

Disagree (0)

Strongly disagree (0)

Overall agree (91)

Strongly agree (45)

Agree (55)

Not sure (0)

Disagree (0)

Strongly disagree (0)

Overall agree (100)

Strongly agree (0)

Agree (91)

Not sure (0)

Disagree (9)

Strongly disagree (0)

Overall agree (91) 
other mums, and seeing the development of other babies made me more confident in my own child', and 'I found it really beneficial meeting other moms, and particularly seeing other moms feeding really helped me to feel more confident.'

In addition, every respondent reported that the group contributed to a better understanding of their baby's social and psychological development. This improvement is also clearly demonstrated by the significant increase in participants' reported knowledge of several key terms in developmental psychology between the first and last session: 'child-directed speech' (McNemar's test, $n=11, p=.01$ ), 'social referencing' ( $p=.01$ ), 'prosocial behaviour' ( $p=.01)$ and 'joint/shared attention' ( $p<$ .01 ; see Figure 4). For this analysis, Not sure responses were categorized conservatively as 'not familiar' ('No').

In order to further demonstrate effective public engagement and research impact, it was also critical to know whether the information gained was seen by participants as helpful, and whether they said that they had used this information in their everyday lives. When asked to rate the helpfulness of each educational session, 100 per cent of mothers rated each session as helpful (that is, either 'helpful' or 'very helpful'). We also asked for open-ended written responses regarding the aspects of the group that were most beneficial for mothers' education and well-being, and whether mothers used the information they learned in the sessions at home (see Table 6).

Again, these findings suggest that the ability to share experiences with peers was a key contributor to mothers' sense of improved well-being. However, despite the value of being able to discuss relevant topics with peers, it was the presentations that participants reported as being of most benefit to their education. Quotations from

Figure 4: Mothers' reported knowledge of concepts in developmental psychology at Session 1 (see Figure 3) and Session 6 (final session); note: Figure 3 has 14 respondents, whereas this figure contains only those 11 who responded in both questionnaires (source: author)

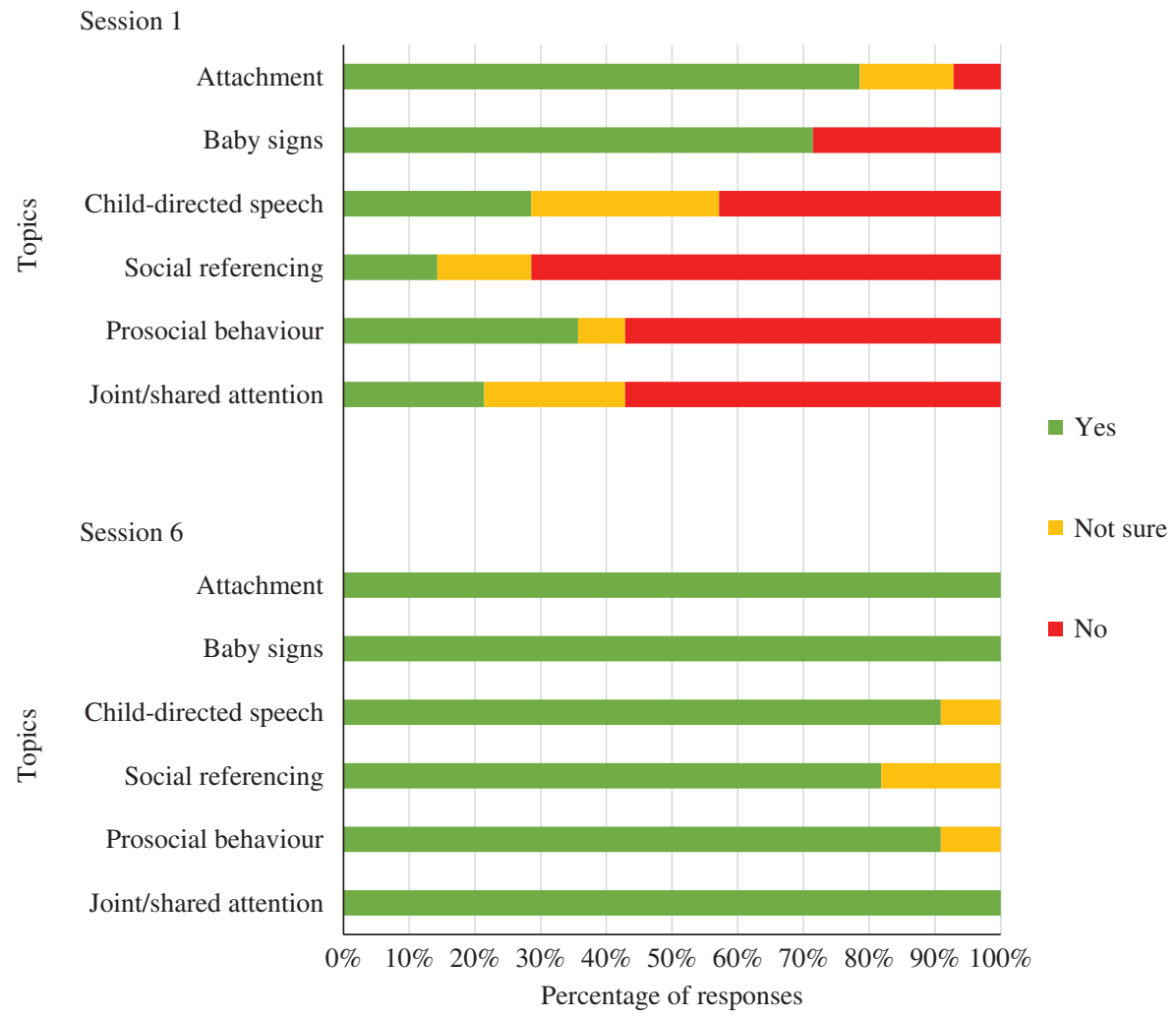




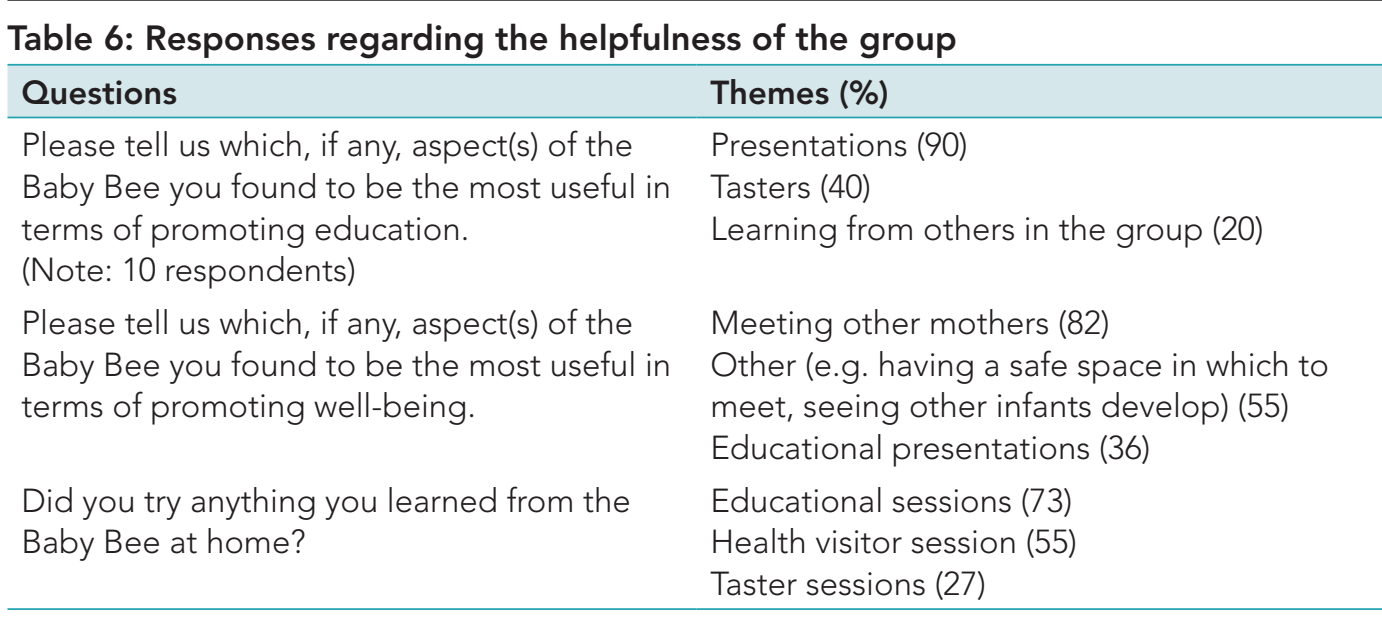

participants included statements such as: 'Honestly, I really enjoyed all the sessions, and felt like I learned something from each one. I appreciated how holistic the education was too'; and, 'The short talks about development were very interesting.'

It could have been the case that the group would have been just as beneficial without the educational components - that peer interaction provided all the relevant benefits to well-being and education. The data suggest that this was not the case that the educational aspect of the group was an integral part of its success and was perceived as a genuine benefit of the group.

All mothers reported using at least some aspect of what they had learned in the group in their day-to-day life. The majority of responses given were related to the academic-led educational sessions, demonstrating how one aspect of our impact goal was fulfilled: our research was taken up and used in practical ways by group participants. For example, mothers had learned that infants enjoy connecting with others through being imitated (for example, Carpenter et al., 2013), and they tried this out at home. One mother also described using child-directed speech after having learned about its value from the group. Mothers also reported using sleeping and feeding tips from the health visitor session, and reported replicating activities that they had learned about through the taster sessions.

\section{Summary}

Thus, the group was valuable not solely as a social gathering, but also as a place to learn new, helpful information - information that mothers reported using at home. Topics introduced by the lab ended up being a highly valued aspect of the educational component, despite the generally low interest in this seen in responses to the initial pre-group questionnaire (see Table 3). The group thus fulfilled its aim of being a source of public engagement and research impact: research was effectively communicated to the public and applied in a way that provided tangible benefits to families' education and well-being. Given Besley and colleagues' (2018) findings that the expected effectiveness of outreach activities is a key motivator for researchers, these findings should be encouraging for researchers who are not sure if their outreach efforts will be well received and effective.

\section{Research participation and the future of the group}

We were clear throughout that participation in the group was in no way contingent on participating in lab research. However, all 15 of the mothers who participated in the 
group ended up either participating in the lab's research (14) or informally expressing interest in participating (1). We believe that the high uptake rate was, on the one hand, due to interest in the research stemming from the educational sessions, and, on the other hand, due to the social connections and trust established between mothers, infants and the lab team. This approach fitted well with our surroundings and needs. For the longitudinal study we were working on at the time, it was particularly important for us to develop strong relationships with a relatively small group of mothers.

For baby and child labs hoping to recruit hundreds of infants every year, such an approach would have to be adapted. However, as a baby and child lab in a small town, working with smaller sample sizes, we found this approach to be highly effective. For baby and child labs that are starting from scratch and looking to build new networks with local families - even those with older children - such an approach would also be helpful. The approach of creating education and support groups in one's lab could be beneficial for researchers who work with other (for example, clinical) populations as well. The benefits to recruitment do not end with the mothers who directly take part in the group. From these participants, word spreads to friends, and the lab's visibility in the town grows. The organizations with whom we have established a relationship are also supportive in our recruitment efforts. In the year following the launch of the Baby Bee, we saw the number of participant sign-ups increase substantially, without much further effort. We had 21 participants sign up during the year prior to the launch of ABC Communities, and 91 signed up during the year following the launch. This total includes parents who signed up through the Baby Bee directly, those who received flyers from the birth registry, those who found out about the research from health visitors, and those who found out about the research from friends or our online pages.

Negotiating the relation between public engagement activities and recruitment was a key challenge. We aimed to be as transparent as possible with the mothers, being clear that their attendance in the group was not contingent on research participation, while being open about the fact that, as a baby and child lab, research is central to what we do. This meant being unembarrassed to say that we are always looking for new participants. Public engagement, impact and recruitment can thus be intertwined, mutually supporting activities.

In light of Besley and colleagues' (2018) findings that researchers are more likely to engage in outreach if they expect to enjoy it, it is also relevant to mention that all of us who helped with the group and presented research found the experience very enjoyable. The mothers were interested in the presentations, and engaged in discussions about the research. We saw the babies grow and change from session to session, and welcomed new arrivals. The group became (and continues to be) an enjoyable part of the life of the lab.

The mothers enjoyed the group too, with 11 out of 11 respondents saying in the sixth session that they hoped that the group would continue. With this positive feedback, we decided to keep the group running, although, to save time, with fewer regular taster sessions and educational components. Older babies have 'graduated' (once they start crawling), and new babies and mothers have joined. This has been an organic process, with minimal new recruiting efforts besides fortnightly reminder posts on our Facebook page. New members have found the group through these Facebook posts, as well as through various local and university events calendars that have started to list the group. New members also hear about the group through word of mouth, having been invited by friends in the group, or having heard about the group through parents at other local activities. The group plays a real role in the local infant community, continuing to run and keep a consistent size with minimal effort and cost on our part. 


\section{Conclusion}

Here we have described one approach to addressing the challenges of public engagement, research impact and research participation that are faced by many baby and child labs. We are not the first baby and child lab to run a baby group, nor do we claim that such an approach is suitable for every context. However, we have shown that the approach we took allowed us to effectively and enjoyably demonstrate research impact through public engagement, and that it has generated sustained research participation despite starting our infant recruitment efforts from the ground up.

The strategy we have outlined will be especially pertinent to those small or growing research groups that are held back by recruitment challenges. However, the approach we outline to forming genuine connections with local communities to deliver relevant and helpful educational information is useful to researchers regardless of location, resources or topic of study. Research labs often function in a transactional manner: participants are brought to a lab, complete a task and leave. Their engagement with the lab and the research that takes place there can be limited. Regardless of their size, research labs can seek out ways to foster community engagement and collaborative, rather than transactional, research participation.

Through listening to the local infant community and identifying key areas of need, we were able to provide relevant and useful resources. The issues we identified were a need for increased community interconnectedness and social spaces for pregnant women and mothers of young infants. It is likely that these are common issues. Baby and child labs will often be ideally suited to functioning as such social spaces, having already been designed for parents' and children's safety and comfort.

In future, we hope to build on the success of the group. For example, we are exploring ways to support local fathers, who face their own unique set of challenges. In our efforts so far, we have found that establishing an education and support group for fathers is difficult. The short length of paternity leave and the tendency for mothers to be the primary caregiver mean that it is harder for fathers to commit time to such a group. As such, other approaches may be more effective, such as one-off educational events.

We also want to encourage research participation from, and public engagement with, socio-economically and ethnically diverse populations (Nielsen et al., 2017). Families with lower socio-economic status and certain minority ethnic groups are widely under-represented in higher education (Boliver, 2013; Crawford et al., 2016), and thus it may be the case that the university is not seen as an accessible institution for these families. One of our aims going forward is to establish whether the group participants really were representative of the range of backgrounds that exist in the local community. If not, a way of making programmes such as these more accessible to a more diverse group of participants is to identify community network 'brokers' (Morgan-Trimmer, 2014) who can enable new connections to be formed between the lab and local community members who may not view university-associated activities as accessible. However, we want to avoid families feeling targeted on the basis of their socio-economic status or ethnicity, meaning that sensitivity is needed to find appropriate avenues to engage with the full range of local families.

In summary, baby and child labs have unique opportunities to engage their local infant community, but time pressures and fears about enjoyment and effectiveness can serve as an obstacle to taking these opportunities (Besley et al., 2018). We have outlined a strategy that is low cost, easy to implement, enjoyable and effective. We have described how other baby and child labs could employ a similar strategy, but we also believe that this approach is relevant across different disciplines. By listening to 
local stakeholders and employing a dynamic, multidirectional approach to knowledge transfer (Ward et al., 2009), researchers can effectively identify contextually appropriate modes of engagement, as well as relevant and useful discussion topics. For baby and child labs, by providing helpful educational resources and offering a place where parents can meet others to share similar experiences, researchers can contribute to the education and well-being of local families. Taking this collaborative stance is also useful in recruitment efforts, helping to move beyond merely 'parachuting in' to the local community to find participants. We hope the strategy we have described will help encourage a 'culture of engagement' (Wilson et al., 2014) in baby and child labs, as well as in other types of research labs, and that public engagement, research impact and research participation come to be seen as interlinked, mutually supporting and enjoyable goals.

\section{Acknowledgements}

Many thanks to all the mothers and infants who participated in this project, as well as those who continue to be part of the ABC Baby Bee. Thanks also to all those local groups and businesses that have been part of the $A B C$ Communities initiative, and that contributed taster sessions to the Baby Bee. A particular thanks to the Health Visitor team for North East Fife for the educational support they provided. We are also grateful to the many research assistants and PhD students who assisted with the project. A final thank you goes to the University of St Andrews for the funding provided to make this project possible.

\section{Notes on the contributors}

Gideon Salter is a PhD student in developmental psychology at the University of St Andrews, UK. His research investigates the developmental origins of shared experience, focusing particularly on the emergence of joint attention and communication in infancy. His research makes use of a variety of methodologies, including experimental, observational and interview methods. He is also active in engaging the public with his research, with a particular interest in reaching out to families with infants.

Tina Altdörfer's research interests focus on the social and cognitive development of children and great apes. She studied in the master's programme in early childhood research at Leipzig University, Germany, and has completed research internships at the Uppsala Child and Baby Lab, Sweden, and the University of St Andrews Baby and Child Lab, UK. Her master's research involved conducting eye-tracking research investigating the social understanding of children and chimpanzees.

Geraldine Brown began her research career as a research fellow at the University of Strathclyde, UK. During this time, her main research focus was on the impact of financial instruments on regional development. She subsequently retrained as a chartered teacher. Having taught in schools for over 13 years, she returned to academia as Lab Manager of the University of St Andrews Baby and Child Lab, UK. Her research interests span a wide spectrum of areas relating to the cognitive and social development of children.

Malinda Carpenter is a professor of developmental psychology at the University of St Andrews, UK. She got her PhD from Emory University, USA, did postdoctoral research at the University of Denver, USA, and the University of Liverpool, UK, and then worked 
in the Department of Developmental and Comparative Psychology at the Max Planck Institute for Evolutionary Anthropology in Germany. Her main research interests are in children's social and prosocial development.

\section{References}

Besley, J.C., Dudo, A. and Storksdieck, M. (2015) 'Scientists' views about communication training'. Journal of Research in Science Teaching, 52 (2), 199-220. https://doi.org/10.1002/tea.21186.

Besley, J.C., Dudo, A., Yuan, S. and Lawrence, F. (2018) 'Understanding scientists' willingness to engage'. Science Communication, 40 (5), 559-90. https://doi.org/10.1177/1075547018786561.

Boliver, V. (2013) 'How fair is access to more prestigious UK universities?'. The British Journal of Sociology, 64 (2), 344-64. https://doi.org/10.1111/1468-4446.12021.

Brand, R.J., Gans, R.T., Himes, M.M. and Libster, N.R. (2019) 'Playdates: A win-win-win strategy for recruitment of infant participants'. Infancy, 24 (1), 110-15. https://doi.org/10.1111/infa.12269.

Burns, T.W., O'Connor, D.J. and Stocklmayer, S.M. (2003) 'Science communication: A contemporary definition'. Public Understanding of Science, 12 (2), 183-202. https://doi.org/10.1177/ 09636625030122004.

Carpenter, M., Uebel, J. and Tomasello, M. (2013) 'Being mimicked increases prosocial behaviour in 18-month-old infants'. Child Development, 84 (5), 1511-18. https://doi.org/10.1111/cdev.12083.

Crawford, C., Gregg, P., Macmillan, L., Vignoles, A. and Wyness, G. (2016) 'Higher education, career opportunities, and intergenerational inequality'. Oxford Review of Economic Policy, 32 (4), 553-75. https://doi.org/10.1093/oxrep/grw030.

Duncan, S. and Oliver, S. (2017) 'Editorial: Motivations for engagement'. Research for All, 1 (2), 229-33. https://doi.org/10.18546/RFA.01.2.01.

Ecklund, E.H., James, S.A. and Lincoln, A.E. (2012) 'How academic biologists and physicists view science outreach'. PLoS One, 7 (5), e36240. https://doi.org/10.1371/journal. pone.0036240.

EC (European Commission) (2020) 'Horizon Impact Award'. Accessed 2 February 2021. https://ec.europa.eu/info/research-and-innovation/funding/funding-opportunities/prizes/ horizon-impact-award_en\&pk_campaign=rtd_news\#what.

ERC (European Research Council) (2019) 'Communicating your research'. Accessed 2 February 2021. https://erc.europa.eu/managing-your-project/communicating-your-research.

Hagger-Johnson, G., Hegarty, P., Barker, M. and Richards, C. (2013) 'Public engagement, knowledge transfer, and impact validity'. Journal of Social Issues, 69 (4), 664-83. https://doi.org/10.1111/ josi.12035.

Loudon, K., Buchanan, S. and Ruthven, I. (2016) 'The everyday life information seeking behaviours of first-time mothers'. Journal of Documentation, 72 (1), 24-46. https://doi.org/10.1108/jd-06-20140080.

Morgan-Trimmer, S. (2014) '"It's who you know": Community empowerment through network brokers'. Community Development Journal, 49 (3), 458-72. https://doi.org/10.1093/cdj/bst049.

Nielsen, M., Haun, D., Kärtner, J. and Legare, C.H. (2017) 'The persistent sampling bias in developmental psychology: A call to action'. Journal of Experimental Child Psychology, 162, 31-8. http://doi.org/10.1016/j.jecp.2017.04.017.

RCUK (Research Councils UK) (2010) Concordat for Engaging the Public with Research: A set of principles drawn up by the funders of research in the UK. Accessed 2 February 2021. www.ukri.org/files/legacy/scisoc/concordatforengagingthepublicwithresearch-pdf/.

REF2021 (2020) Index of Revisions to the 'Guidance on Submissions' (2019/01). Accessed 2 February 2021. www.ref.ac.uk/media/1092/ref-2019_01-guidance-on-submissions.pdf.

Scottish Government (2016) Scottish Index of Multiple Deprivation 2016: Introductory booklet. Accessed 2 February 2021. www2.gov.scot/Resource/0050/00504809.pdf.

Ward, V., House, A. and Hamer, S. (2009) 'Developing a framework for transferring knowledge into action: A thematic analysis of the literature'. Journal of Health Services Research \& Policy, 14 (3), 156-64. https://doi.org/10.1258/jhsrp.2009.008120.

WHO (World Health Organization) (2002) Global Strategy for Infant and Young Child Feeding. Accessed 2 February 2021. https://apps.who.int/iris/bitstream/handle/10665/42590/9241562218. pdf.

Wilson, C., Manners, P. and Duncan, S. (2014) Building an Engaged Future for UK Higher Education: Full report from the Engaged Futures consultation. Bristol: National Co-ordinating Centre for Public Engagement. Accessed 2 February 2021. www.publicengagement.ac.uk/sites/default/ files/publication/t64422_-_engaged_futures_final_report_72.pdf. 